\title{
The ecological genetics of introduced populations of the Giant Toad, Bufo marinus. IV. Gene flow estimated from admixture in Australian populations
}

\author{
Simon Easteal
}

\author{
Department of Population Biology, Research School \\ of Biological Sciences, The Australian National \\ University Canberra, A.C.T. 2601, Australia.
}

\begin{abstract}
Allele frequency variation is described at nine polymorphic enzyme loci in 21 samples from populations of the introduced Giant Toad, Bufo marinus, in the region of Townsville in north Queensland, Australia. Some of these populations appear to have been established through the introgression of other populations that previously had been isolated. Comparisons of allele frequencies at three polymorphic loci between the introgressed populations and the original populations are used to obtain admixture estimates. These are used to estimate a rate of gene flow among the populations of approximately $2 \mathrm{~km} /$ year. This is consistent with an estimate based on the rate at which Bufo marinus has colonised new areas in Australia when discontinuities in the pattern of this colonisation are taken into account. The estimate of gene flow is combined with published data on population density to estimate neighbourhood size. The estimate obtained is substantially greater than the effective population size estimate determined previously from data on allele frequency variances in other populations. This discrepancy is most likely due to inaccuracies in the population density estimates, to underestimates of the extent of offspring number variance and perhaps to occasional departures from sex ratio parity. It has important implications for the study of the genetic structure of populations which are discussed.
\end{abstract}

\section{INTRODUCTION}

Generalisations about gene flow and its importance as a cohesive force in evolution (Mayr, 1963; Ehrlich and Raven, 1969; Stanley, 1979) have little empirical basis. Direct estimation of gene flow has been achieved in few species and then only on a limited scale (Schaal, 1980; Handel, 1983; Baker, 1981; Singleton and Hay, 1983). The difficulties usually encountered in attempting direct estimation have led most workers to use indirect methods. There have been three general approaches. In the first, the dispersal of individuals is determined on the assumption that the movement of individuals is approximately equivalent to the movement of genes (e.g., Endler, 1977; Gill, 1978; Jones et al., 1981; Patton and Feder, 1981; Coyne et al., 1982; McCauley, 1983). The second approach involves the estimation of the standardised variance $\left(F_{S T}\right)$ of gene frequencies among populations, on the assumption that this is a function of the extent of gene flow between them (Endler, 1977; Eanes and

Present address: Department of Zoology, The University of Oklahoma, Norman, Oklahoma 73019, U.S.A.
Koehn, 1978; Daly, 1981; Zera, 1981). The third approach is suggested by Slatkin (1981), who showed that an allele's average frequency among local populations, conditioned by the number of local populations in which it occurs, is largely independent of selection intensity and mutation rate, but is strongly dependent on gene flow $(m)$ and effective population size $\left(N_{e}\right)$. This "conditional average allele frequency" $\left(p_{i}\right)$ can be used as an estimate of the compound parameter $N_{e} m$, as demonstrated by Larson et al. (1983).

There are problems with all three of these approaches. The relationship between dispersal and gene flow may be complicated by the breeding and social behaviour of the species and for this and other reasons, discussed by Endler (1977), it is generally supposed that gene flow is spatially restricted in relation to dispersal, at least in animal species. The extent to which this is the case has not been determined in any particular instance, but estimates of dispersal will tend generally to be overestimates of gene flow. Allele frequency variances are affected by population size and by natural selection as well as by gene flow. Only when the effective sizes of populations are known 
and the effects of selection are either known, or can be assumed to be negligible, can the extent of gene flow be inferred from allele frequency variances among populations. Similarly, the conditional average allele frequency depends on both effective population size and gene flow, and gene flow cannot be determined from estimation of $p_{i}$ without an independent estimate of $N_{e}$.

In human populations gene flow has been estimated directly by studying the changes in gene frequencies which result from admixture of previously isolated, genetically different populations, particularly of Caucasians, Amerindians and Blacks in North and South America (e.g., Workman, 1973; Ward and Neel, 1976; Crawford et al., 1981; Franco et al., 1982). This approach is made possible by the availability of information on the demographic history of these populations. Such information usually does not exist for populations of other species, so that the approach has not been applied except to humans.

I apply the approach here to populations of the neotropical Giant Toad, Bufo marinus, whose introduction and spread in Australia have been well documented. Admixture is determined in populations in the Townsville region of north Queensland, that appear to lie between three populations established in isolation from each other 35 to 40 years ago, and which were formed as these earlier established populations expanded towards each other and merged. The admixture estimates will be used to infer rates of gene flow.

The gene flow estimate presented here will be discussed in relation to the rates at which $B$. marinus has dispersed into new areas in Australia (Easteal and Floyd, 1985) and to estimates of the effective size of $B$. marinus populations in Hawaii and Australia (Easteal, 1985a).

\section{MATERIALS AND METHODS}

One-thousand, nine-hundred and seventy-four toads were collected in 1979 and 1980 from 21 localities in the area of Townsville. Specimens were transported live to the laboratory where they were killed either by pithing or freezing. All methods of tissue preparation, electrophoresis and histochemical staining are as described in Easteal $(1982 ; 1985 a)$. All explanations of locus nomenclature and its abbreviation can also be found in these other publications. Electrophoresis was performed using horizontal 12 per cent starch gels or cellulose acetate plates.
Allele frequencies were weighted for sample size in calculating their means and variances. The genetic identities $(I)$ and genetic distances $(D)$ between populations were calculated by the method of Nei (1978). Populations were clustered in dendrograms of genetic relatedness using the unweighted pair group method of Sneath and Sokal (1973). The computer program BIOSYS (written by D. L. Swofford and R. B. Selander) was used in estimating $I$ and $D$ and in the construction of the dendrograms.

\section{HISTORICAL BACKGROUND}

B. marinus was introduced to Australia from Hawaii in 1935 and by 1937 had been released throughout the sugar-cane growing districts of Queensland (Easteal, 1981). Sabath et al. (1981), Easteal et al. (1985) and Easteal and Floyd (1985) have described the subsequent spread of the species in Queensland, based on distribution and first sighting records compiled by Floyd et al. (1981). Large numbers of toads are known to have been released in the Ingham/Bambaroo and Giru/Ayr districts between 1936 and 1937 (Mungomery, 1937). These districts are approximately 100 kilometres north-north-west and 50 kilometres south-east of Townsville respectively. Floyd et al. (1981) record sightings of $B$. marinus in both districts in or before 1940 , confirming that populations were successfully established from both releases. Toads were first seen in Townsville at Mundingburra in 1944 and at Pimlico in 1945. These are adjacent suburbs, north of the Ross River, in the city of Townsville. There are no reported sightings from the areas directly between either Ingham/Bambaroo and Townsville or between Giru/Ayr and Townsville until 1974. In 1948 there were sightings at Calcium and Reid River to the south of Townsville (fig. 1).

It can hence be presumed that $B$. marinus was established in Townsville by 1944-45 and in the Calcium/Reid River area by 1948. Although we do not know the sources of either population, both localities are closer to the Giru/Ayr district than to any of the other districts in which $B$. marinus was originally released or in which it occurred before 1945 . It seems most likely therefore that the Townsville and Calcium/Reid River toads are derived from the Giru/Ayr population. It is not however critical to assume this in the analyses that follow. 


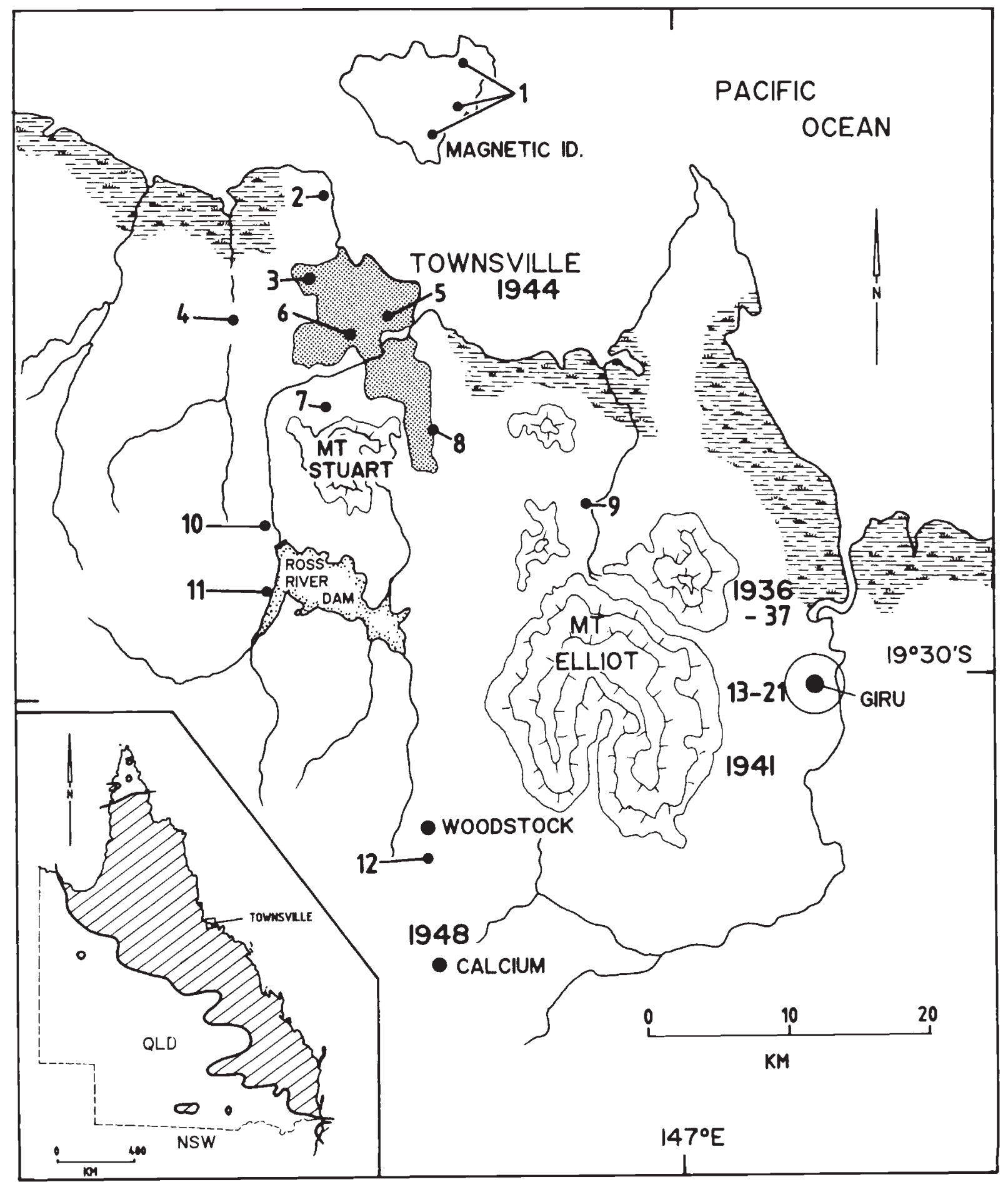

Figure 1 Diagram of study site, showing position of sample localities (1-21), location and dates of first sighting records of Bufo marinus, and the main geographical features of the area. 


\section{RESULTS}

\section{Allele frequency variation}

Twenty-one loci were scored. Twelve of these were monomorphic in all 21 populations. The allele frequencies of the remaining nine polymorphic loci are listed in table 1. At several loci, particularly $I d d h, M d h: \mathrm{NADP}_{1}^{+}$, and Sod, there are large allele frequency differences between the Magnetic Island population (1) and all other populations. It seems likely that these differences arose substantially as a result of genetic drift associated with a population size bottleneck which occurred at the time the toads were introduced to the island, rather than through the action of natural selection. This is indicated by: 1 . The lack of several rare alleles in the Magnetic Island population which occur in mainland populations (Est:210, Est:270, Hbdh:F, and $\left.M d h: \mathrm{NADP}_{2}^{+}: \mathrm{F}\right)$. 2. Several independent reports from local residents that only "a handful" of toads were deliberately brought to the island not more than 15 years ago. 3. Comparison with the results of a separate study (Easteal, 1985a) in which allele frequencies were determined in 10 populations, also known to have been recently established, in both Hawaii and Australia. The allele frequency differences among these other populations, which are in climatically diverse and widely separated localities, are far less than the differences between Magnetic Island and the mainland populations, which are in climatically similar localities, separated by only a few kilometres. It seems unlikely that greater selective regime differences exist between the Magnetic Island and mainland populations than among the Hawaiian and other Australian populations; unlikely therefore that the Magnetic Island differences have resulted from the differential effects of natural selection.

Among the mainland populations there is also allele frequency variation. This was estimated as $F_{S T}=\sigma^{2} / \bar{p}(1-\bar{p})$, where $\sigma^{2}$ is the variance of allele frequencies among populations (corrected for sampling error variance as described by Easteal, $1985 a$ ) and $\bar{p}$ is the mean allele frequency among populations. Significance of allele frequency variation among populations was tested using the method of Workman and Niswander (1969).

Among all mainland populations there is highly significant allele frequency variation $(p<0.0001)$ at five of the nine polymorphic loci and no significant variation at the remaining four loci (table 2 ). Among populations in the city of Townsville $(2-7)$, and among populations surrounding the town of Giru (13-21) there is no significant variation at any locus. The weighted mean frequencies for these two homogeneous regions are in table 1 .

The pattern of genetic relatedness (fig. 2) based on genetic distances (table 3) confirms that the Magnetic Island population is genetically distinct from all others. It is also in agreement with the analysis of allele frequency variances in showing

Table 1 Per cent allele frequencies at nine polymorphic loci in Bufo marinus populations in the Townsville area. $\bar{N}=$ mean sample size

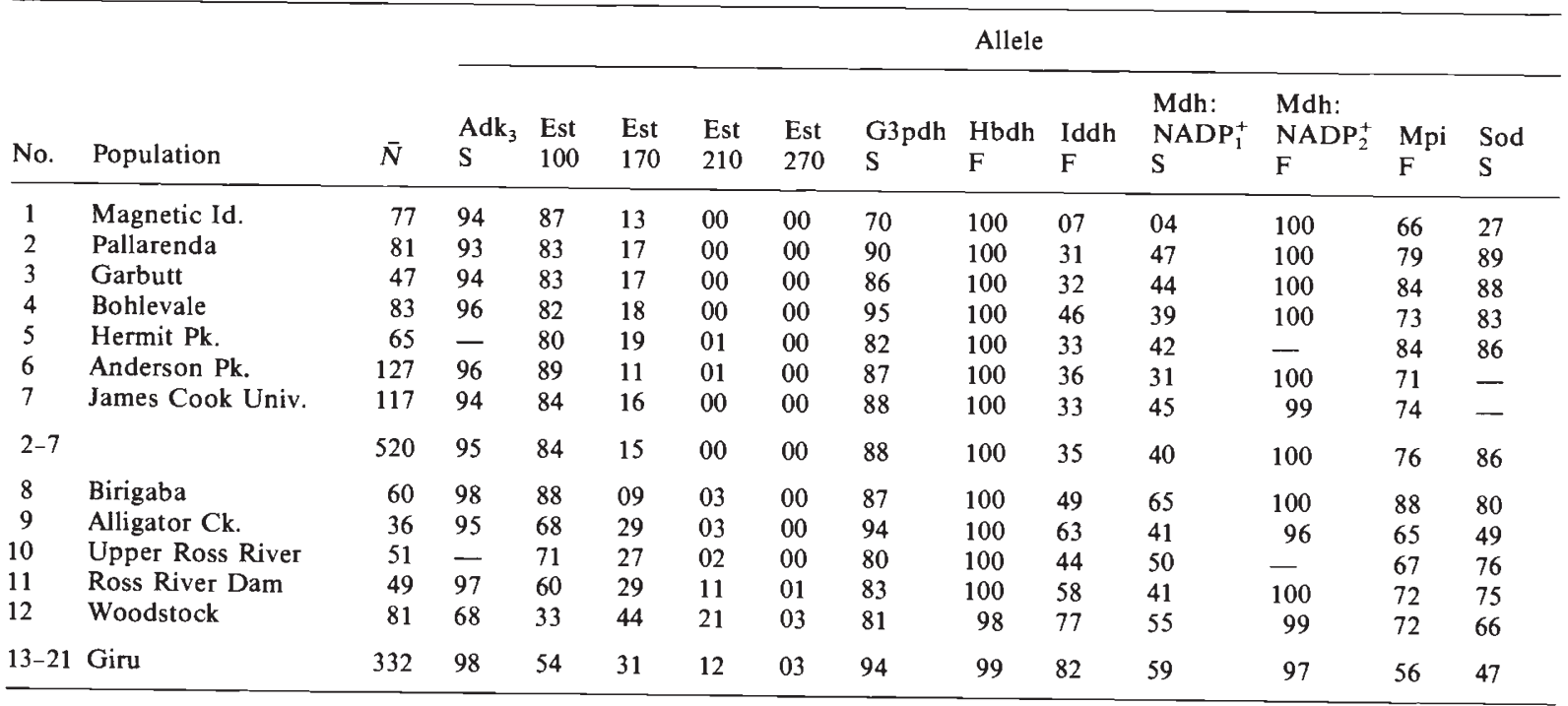




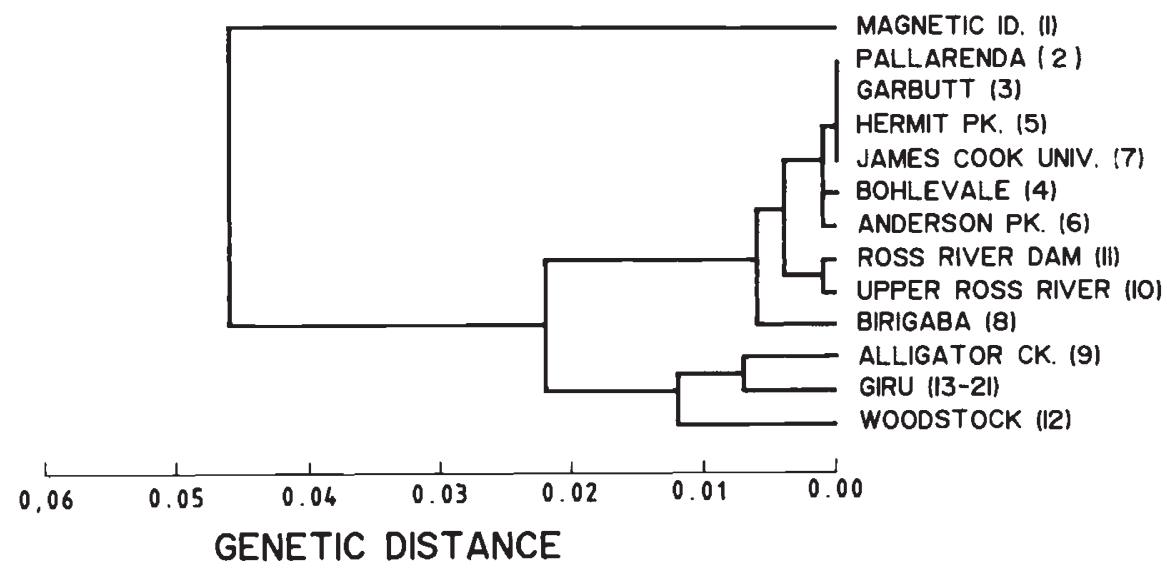

Figure 2 Dendrogram of genetic relatedness derived from genetic distances among populations sampled in the Townsville region.

The spatial locations of the populations are shown in fig. 1.

genetic uniformity of the populations in the city of Townsville (2-7), and the fact that these are distinct from those at Giru (13-21). It indicates that, of the five populations outside these two areas, three (Ross River Dam (11), Upper Ross River (10) and Birigaba (8)) are similar to the Townsville City populations, and that the other two (Alligator Creek (9) and Woodstock (12)) are genetically more similar to the Giru populations. Although the genetic distance estimates are insufficiently precise to rule out other possible patterns of relatedness, the pattern shown in fig. 2 corresponds well with the geographical positions of the populations (fig. 1) and agrees with the patterns of similarity and difference indicated by the allele frequency variance analysis.

Of the localities sampled, Giru is the only one which was a site of original release of toads in Australia. The ten populations originally released in Australia and Hawaii were all established with large numbers of individuals from the same source population. It can be assumed therefore that initially they all had approximately the same allele frequencies at polymorphic loci (Easteal, 1985a). The Giru and the Woodstock populations are not genetically distinct from the other initial-release populations whereas the Townsville populations, which are derived from them, are distinct (fig. 3 ). This would suggest that the allele frequency changes that gave rise to the differences between the Townsville populations and those at Woodstock and Giru occurred substantially in the Townsville populations.

It seems likely that these changes have resulted mainly from genetic drift rather than natural selection. As in the case of the Magnetic Island population, there are rare alleles which occur in almost all the original release populations but which are absent in all the Townsville populations. Also, it seems unlikely that greater selective regime

Table 2 Standardised variances of allele frequencies $\left(F_{S T}\right)$ for mainland populations of Bufo marinus in the Townsville area. 2-21: All mainland populations; 2-7: Populations in the city of Townsville; 13-21: Populations around the town of Giru. $\chi^{2}$ tests are used to test if the variances are significantly greater than 0

\begin{tabular}{|c|c|c|c|c|c|c|c|c|c|}
\hline Allele & $\begin{array}{l}F_{S T} \\
(2-21)\end{array}$ & $x^{2}[20]$ & $p$ & $\begin{array}{l}F_{S T} \\
(2-7)\end{array}$ & $\chi^{2}[5]$ & $p$ & $\begin{array}{l}F_{S T} \\
(13-21)\end{array}$ & $\chi^{2}[9]$ & $p$ \\
\hline $\operatorname{Adk}_{3}: \mathrm{S}$ & $0 \cdot 117$ & 264 & $<0.0001$ & $0 \cdot 004$ & $4 \cdot 16$ & $>0.05$ & 0.008 & $5 \cdot 31$ & $>0.05$ \\
\hline Est $: 100$ & $0 \cdot 011$ & $24 \cdot 8$ & $>0.05$ & $0 \cdot 006$ & $6 \cdot 24$ & $>0.05$ & 0.007 & $4 \cdot 65$ & $>0.05$ \\
\hline Est $: 170$ & 0.059 & 133 & $<0.0001$ & $0 \cdot 008$ & $8 \cdot 32$ & $>0.05$ & 0.002 & $1 \cdot 33$ & $>0.05$ \\
\hline G3pdh:S & $0 \cdot 013$ & $29 \cdot 4$ & $>0.05$ & $0 \cdot 007$ & $7 \cdot 28$ & $>0.05$ & - & - & \\
\hline$I d d h: \mathrm{F}$ & $0 \cdot 192$ & $433 \cdot 5$ & $<0.0001$ & 0.009 & $9 \cdot 36$ & $>0.05$ & 0.006 & $3 \cdot 98$ & $>0.05$ \\
\hline$M d h: \mathrm{NADP}_{1}^{+}: \mathrm{S}$ & 0.038 & $85 \cdot 8$ & $<0.0001$ & 0.009 & $9 \cdot 36$ & $>0.05$ & $0 \cdot 005$ & $3 \cdot 32$ & $>0.05$ \\
\hline$M d h: \mathrm{NADP}_{2}^{+}: \mathrm{F}$ & 0.009 & $20 \cdot 3$ & $>0.05$ & 0.008 & $8 \cdot 32$ & $>0.05$ & $0 \cdot 010$ & $6 \cdot 64$ & $>0.05$ \\
\hline$M p i: \mathrm{S}$ & 0.000 & 0 & $>0.05$ & 0.008 & $8 \cdot 32$ & $>0.05$ & 0.009 & $5 \cdot 98$ & $>0.05$ \\
\hline Sod:S & $0 \cdot 129$ & 291 & $<0.0001$ & 0.006 & $6 \cdot 24$ & $>0.05$ & 0.003 & 1.99 & $>0.05$ \\
\hline $\bar{F}_{S T}$ & 0.063 & & & $0 \cdot 007$ & & & 0.006 & & \\
\hline
\end{tabular}


Table 3 Matrix of genetic similarity (I) (above diagonal) and genetic distance (d) (below diagonal) for 13 B. marinus populations in the Townsville region

\begin{tabular}{|c|c|c|c|c|c|c|c|c|c|c|c|c|c|c|}
\hline \multicolumn{2}{|c|}{ Population } & \multirow[t]{2}{*}{1} & \multirow{2}{*}{$\begin{array}{l}2 \\
0.958\end{array}$} & \multirow{2}{*}{$\begin{array}{l}3 \\
0.961\end{array}$} & \multirow{2}{*}{$\begin{array}{l}4 \\
0.960\end{array}$} & \multirow{2}{*}{$\begin{array}{l}5 \\
0.963\end{array}$} & \multirow{2}{*}{$\begin{array}{l}6 \\
0.967\end{array}$} & \multirow{2}{*}{$\begin{array}{l}7 \\
0.962\end{array}$} & \multirow{2}{*}{$\begin{array}{l}8 \\
0.944\end{array}$} & \multirow{2}{*}{$\frac{9}{0.964}$} & \multirow{2}{*}{$\begin{array}{l}10 \\
0 \cdot 961\end{array}$} & \multirow{2}{*}{$\begin{array}{l}11 \\
0.957\end{array}$} & \multirow{2}{*}{$\begin{array}{l}12 \\
0.929\end{array}$} & \multirow{2}{*}{$\frac{13-21}{0.934}$} \\
\hline 1 & Magnetic Id. & & & & & & & & & & & & & \\
\hline 2 & Pallarenda & 0.043 & & $1 \cdot 000$ & 0.998 & $1 \cdot 000$ & 0.998 & 1.000 & 0.996 & 0.982 & 0.997 & 0.993 & 0.971 & 0.965 \\
\hline 4 & Bohlevale & 0.041 & 0.002 & 0.001 & & 0.998 & 0.999 & 0.999 & 0.994 & 0.991 & 0.998 & 0.997 & 0.979 & 0.976 \\
\hline 5 & Hermit Pk. & 0.038 & 0.000 & 0.000 & 0.002 & & 0.998 & $1 \cdot 000$ & 0.995 & 0.984 & 0.997 & 0.994 & 0.974 & 0.965 \\
\hline 6 & Anderson Pk. & 0.033 & 0.002 & 0.001 & 0.001 & 0.002 & & 0.999 & 0.991 & 0.985 & 0.996 & 0.993 & 0.969 & 0.967 \\
\hline 9 & Alligator Ck. & 0.036 & 0.018 & 0.017 & 0.009 & 0.017 & 0.015 & 0.015 & 0.015 & & 0.993 & 0.996 & 0.990 & 0.993 \\
\hline 10 & Upper Ross River & 0.040 & 0.003 & 0.003 & 0.002 & 0.003 & 0.004 & 0.002 & 0.005 & 0.007 & & 0.999 & 0.986 & 0.980 \\
\hline 11 & Ross River Dam & 0.044 & 0.008 & 0.007 & 0.003 & 0.006 & 0.007 & 0.006 & 0.008 & 0.004 & 0.001 & & 0.994 & 0.984 \\
\hline 12 & Woodstock & 0.074 & 0.029 & 0.028 & 0.021 & 0.026 & 0.031 & 0.028 & 0.022 & 0.010 & 0.014 & 0.006 & & 0.986 \\
\hline $13-21$ & Giru & 0.068 & 0.036 & 0.036 & 0.024 & 0.036 & 0.034 & 0.032 & 0.024 & 0.007 & 0.020 & 0.016 & 0.014 & \\
\hline
\end{tabular}

differences exist between the habitats in Townsville and those in Giru and Woodstock than exist among the widely separated original release populations.

The allele frequency changes may have occurred in the populations since their establishment or at the time of their establishment. If the changes occurred since establishment (assuming that they resulted substantially from genetic drift), it must be presumed that the effective sizes of the Townsville populations are smaller than those at the original release sites since gene frequency changes have been greater in the Townsville populations and these populations have been in existence for a shorter time. (They were established in 1944-45 as compared with 1932-37 for the other populations.) From field observations, B. marinus

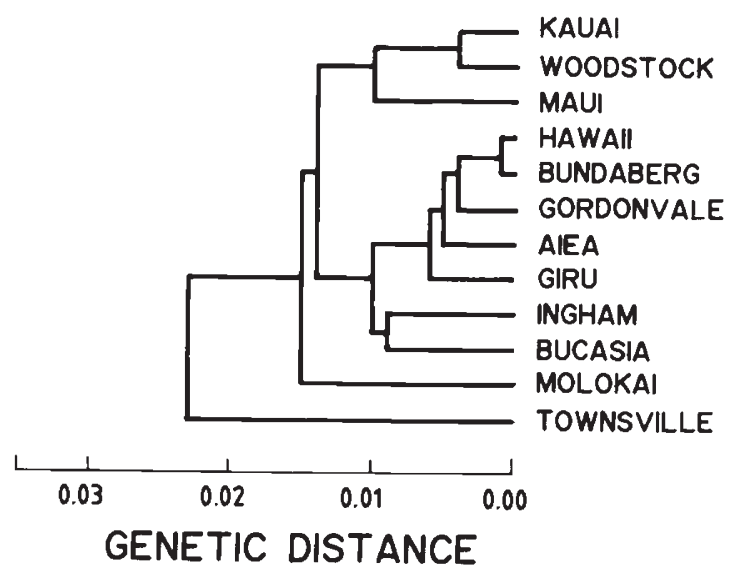

Figure 3 Dendrogram showing the pattern of genetic relatedness of the populations sampled from Townsville, Giru and Woodstock, and those sampled from the other nine sites at which Bufo marinus was initially released in Hawaii and Australia described by Easteal (1985a). would appear to be as (if not more) abundant in and around the city of Townsville than at the original release sites. This and the widespread genetic uniformity among the Townsville populations suggest that these populations are not effectively smaller than those at the initial release sites.

It is more likely that the allele frequency changes occurred when the Townsville populations were established, either by a continuous range expansion through the region with new peripheral areas being successively colonised by a few toads each generation, or from a single "founder effect" accompanying the establishment of an isolated population in Townsville.

The first of these is unlikely. In other regions where populations have been established by continuous range expansion (e.g., on the island of Oahu in Hawaii (Easteal, 1985a) and elsewhere in Queensland (Easteal, 1985b)) there is no evidence of resulting allele frequency changes (although this is not true for discontinuously established populations (Easteal, 1985b)). Also, if the numbers of colonising individuals are approximately the same in each generation the extent of random gene frequency changes will be similar at all stages of a colonising episode and there will be differences between populations throughout the region across which colonisation has occurred. This is not the pattern observed; there are no differences among the populations in the large area around the city of Townsville. Furthermore, as the spatial patterns of allele frequency variation generated by genetic drift during a range expansion are analogous to the temporal patterns of variation produced by genetic drift in a static population (Easteal, 1985b), the direction of change of frequency of successive stages of colonisation is 
independent. Unidirectional changes in frequency will not occur consistently across loci. Hence, at least during the early generations following a range expansion, allele frequencies in the path of colonisation will not be consistently intermediate between the frequencies in the source population and those further along the path. As will be discussed in detail later, the loci at which there are substantial allele frequency differences between the Townsville and the Giru and Woodstock populations all show monotonic patterns of change along both transects between these localities. This further suggests that a continuous range expansion was not responsible for the observed variation.

The production of the variation by a founder event at Townsville would lead to homogeneity of allele frequencies among the Townsville populations and among the source populations, with consistent monotonic changes in frequency between these populations, reflecting the degree to which introgression has occurred as the populations expanded out to meet each other. This is the observed pattern. Assuming that the variation was generated in this way it may be possible to infer rates to gene flow from analysis of the allele frequencies in the populations in the zones of introgression (i.e., those at Alligator Creek, Birigaba, Upper Ross River and Ross River Dam).

\section{Admixture and gene flow estimation}

The degree of admixture $(M)$, which is the proportional genetic contribution of an ancestral population $(a)$ to a mixed population $(m)$ is given by; $M=\left(p_{m}-p_{b}\right) /\left(p_{a}-p_{b}\right)$; where $p_{m}$ is the frequency of an allele in the mixed population and $p_{a}$ and $p_{b}$ are the frequencies of the allele in two ancestral populations (Cavalli-Sforza and Bodmer, 1971). The sampling-error variance of $M\left(\sigma_{M}^{2}\right)$ is given by,

$$
\left.\sigma_{M}^{2}=\frac{1}{\left(p_{a}-p_{b}\right.}\right)\left(\sigma_{p_{m}}^{2}+M^{2} \sigma_{p_{a}}^{2}+(1-M)^{2} \sigma_{p_{b}}^{2}\right),
$$

where $\sigma_{p_{m}}^{2}, \sigma_{p_{a}}^{2}$ and $\sigma_{p_{h}}^{2}=$ the sampling error variances of the allele frequency estimates for the mixed and ancestral populations respectively. The second equation shows that the precision of an estimate of $M$ is strongly dependent on the difference between the allele frequencies in the two ancestral populations. Precise estimates can be obtained only when this difference is large. Admixture estimates for the mixed populations were hence determined only for the three loci with allele frequency differences of 20 per cent or more between the Townsville populations and those at Giru and Woodstock. These loci are Est, Iddh and Sod (table 4). The sampling-error variances in Townsville and Giru were taken as the variances among samples collected in these areas. For the samples collected in the other localities error-variances were taken as the binomial variances of the sizes of the samples collected. At all three loci there is a monotonic change in frequency going both from Townsville to Giru via Birigaba and Alligator Creek, and from Townsville to Woodstock via Upper Ross River and Ross River Dam.

Admixture estimates for each of the four mixed populations are given in table 4. Estimates for different loci should be the same if the admixture results entirely from the action of gene flow. Estimates can be tested for heterogeneity using the expectation that if they are homogeneous,

$$
\chi^{2}=\sum \frac{\left(M_{i}-\bar{M}\right)^{2}}{\sigma_{M_{i}}^{2}}
$$

where $M_{i}$ is the admixture at locus $i, \bar{M}$ is the mean admixture, and $\sigma_{M_{i}}^{2}=$ variance in $M$

Table 4 Percent allele frequencies $(P)$ and their sample error variances $\left(\sigma^{2}\right)$ at the three loci used

\begin{tabular}{|c|c|c|c|c|c|c|}
\hline \multirow[b]{2}{*}{ Locality } & \multicolumn{6}{|c|}{ Locus } \\
\hline & $p$ & $\begin{array}{l}\text { allele } 100) \\
\sigma^{2}\end{array}$ & $p$ & $\begin{array}{l}I d d h \\
\sigma^{2}\end{array}$ & $p$ & $\begin{array}{l}\text { Sod } \\
\sigma^{2}\end{array}$ \\
\hline Giru & $0 \cdot 54$ & 0.0017 & 0.82 & 0.0009 & 0.47 & 0.0008 \\
\hline Alligator Creek & 0.68 & $0 \cdot 0030$ & 0.63 & 0.0032 & 0.49 & $0 \cdot 0034$ \\
\hline Birigaba & $0-88$ & 0.0009 & $0 \cdot 49$ & 0.0020 & $0 \cdot 80$ & 0.0013 \\
\hline Townsville & 0.84 & 0.0008 & $0 \cdot 35$ & 0.0020 & $0 \cdot 86$ & 0.0007 \\
\hline Upper Ross River & $0 \cdot 71$ & 0.0020 & 0.44 & 0.0077 & 0.76 & 0.0017 \\
\hline Ross River Dam & 0.60 & 0.0024 & 0.58 & 0.0025 & 0.75 & 0.0019 \\
\hline Woodstock & $0 \cdot 33$ & 0.0030 & 0.77 & 0.0023 & 0.66 & 0.0029 \\
\hline
\end{tabular}
in the admixture determination 
(Cavalli-Sforza and Bodmer, 1971). There is no heterogeneity among the estimates in any of the four populations (table 4).

The mean admixture estimates shown in table 5 were calculated by weighting each individual estimate by the reciprocal square root of its sample error variance. The relationships between the values of these mean estimates and the geographical positions of the populations are shown in fig. 4. The widths of the zones of introgression between both pairs of ancestral populations were determined by extrapolation through these mean values. The predicted positions of 95 per cent and 5 per cent admixture are marked by crosses on both transects. The predicted lengths of these zones of introgression are $20 \mathrm{~km}$ between Townsville and Giru and $29 \mathrm{~km}$ between Townsville and Woodstock. They may be shorter than this because of the error in the estimates of $M$, but they cannot be any longer, the predicted zones of introgression both border on the city of Townsville in which the populations are known to be genetically uniform.

The centres of the introgression zones (i.e., the locations of the populations with 50 per cent admixture) will correspond to the places where the populations met as they expanded out from their source localities if dispersal has been at the same rate in both directions. Toads were established in (and presumably started dispersing from) Townsville in 1944, Giru in 1937 and Calcium in 1948. The distances between the sites of the original Townsville and Giru populations and the centre of their zone of introgression are $15 \mathrm{~km}$ and $30 \mathrm{~km}$ respectively.

The two populations would have met at the centre of their introgression zone in 1951 if they both spread out at a rate of $2 \mathrm{~km} /$ year. A similar analysis of the Townsville-Woodstock intro- gression zone showed that the populations founded at these two localities could not have dispersed towards each other at the same rate. The centre of the zone is closer to Townsville than to Woodstock, despite the population at Woodstock being of more recent origin (fig. 4). This implies that dispersal from Woodstock towards Townsville has been faster than dispersal in the opposite direction. This may be explained by the fact that toads moving from Woodstock towards Townsville would have followed the Ross River and its tributaries (fig. 1). The construction of the Ross River Dam was more recent than the probable date at which toads moved through the area which the reservoir now covers; it would not therefore have impeded the downstream movement of toads.

The rate of spread of a population into a new area $(\rho)$ is related to the standard deviation of individual dispersal distances $(\sigma)$ and the rate of growth of newly formed populations $(\alpha)$ by the following equation $\rho=\sigma \sqrt{2 \alpha}$ (Skellam, 1951). Easteal and Floyd (1985) used this relationship to determine $2 \sigma$, the root mean square dispersal distance or the radius of a genetic neighbourhood from dispersal data. They did this by assuming that in Bufo marinus $\alpha$ is large enough that in any generation $2 \sigma=\rho$ (which is reasonable given the available data on the species reproductive biology) and that generation time is approximately one year. Assuming a $2 \mathrm{~km} /$ year rate of spread into new areas (i.e., before introgression) along the GiruTownsville transect, this approach gives an estimate for $2 \sigma$ of $2 \mathrm{~km}$ for the populations along this transect.

$2 \sigma$ can also be estimated from the width of the introgression zone or cline ( $w$, the distance between 5 per cent and 95 per cent admixture) using the relationship $2 \sigma \simeq w / 2 \sqrt{T}$, where $T$ is the number

Table 5 Estimates of total admixture $(m)$ and their standard deviations $\left(\sigma_{m}\right)$ loci in four populations in the Townsville region. A $\chi^{2}$ test was used to determine if there was heterogeneity of estimates among loci. Estimates of $M$ were weighted by their reciprocal standard deviations in estimating mean $M(\bar{M})$

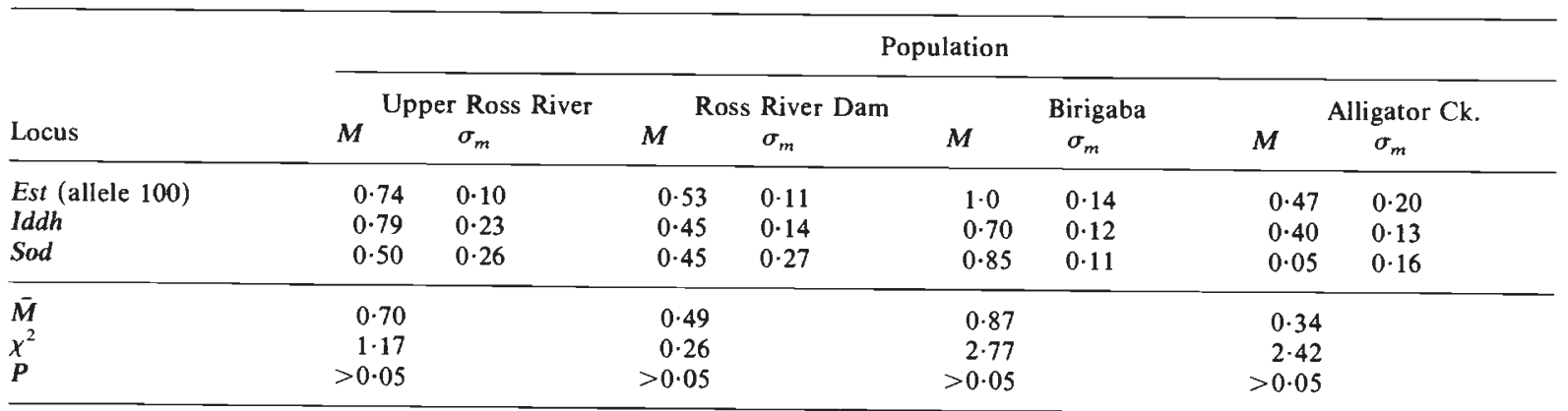




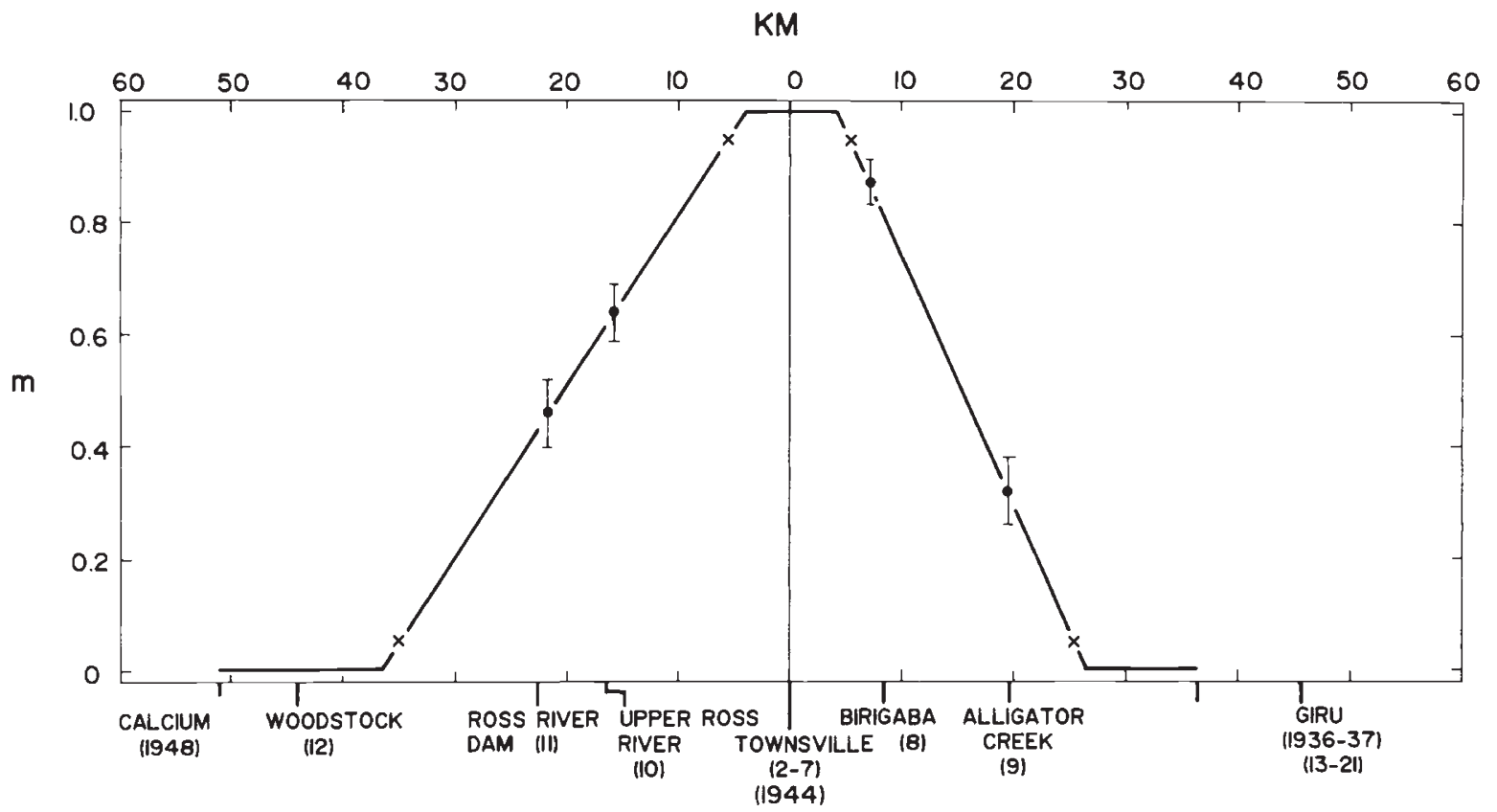

Figure 4 Graphical illustration of zones of introgression between the Townsville (2-7) populations and those at Woodstock (12) and Giru (13-21) derived from admixture estimates in the populations at Birigaba (8), Alligator Creek (9), Ross River Dam (10) and Upper Ross River (11). The standard errors of the admixture estimates are shown. The positions of 5 per cent and 95 per cent admixture are marked by crosses.

of generations since initial contact (Endler, 1977). Along the Giru-Townsville transect, $w=20$ and $T=28$, giving a value for $2 \sigma$ of 1.9 , which is in good agreement with the estimate of $2 \mathrm{~km}$ obtained above from the rate of dispersal into new areas. The apparent difference in the gene flow rate in either direction along the Woodstock-Townsville transect makes impossible an estimate of the rate using this method. The rate in the direction from Woodstock to Townsville does however appear to have been greater than the rate along the GiruTownsville transect.

\section{DISCUSSION}

Easteal and Floyd (1985) estimated $2 \sigma$, from rates of continuous spread into new areas of $B$. marinus' Australian distribution, to be approximately 3$5 \mathrm{~km}$. The estimate of $2 \mathrm{~km}$ obtained here is slightly less than this, although the present study does indicate that $2 \sigma$ may have been greater than $2 \mathrm{~km}$ going from Woodstock to Townsville, and therefore possibly also in other areas. This suggests that Easteal and Floyd's (1985) estimates are reasonably accurate and that the methods used to obtain them are substantially valid.
Easteal and Floyd (1985) combined their estimates of $2 \sigma$ with others of population density, offspring number variance and sex ratio disparity to estimate the sizes of genetic neighbourhoods $(N)$ for different habitats as $N=4 \sigma \pi^{2} d$, where $d$ is the population density (toads $/ \mathrm{km}^{2}$ ). For "semiurban" habitats (such as those at the collection sites in the present study) toads occur at densities of between 1500 and $3000 / \mathrm{km}^{2}$ (Easteal and Floyd, 1985). The estimates of neighbourhood size obtained using these $d$ values and using $2 \sigma$ values of 2,3 and $5 \mathrm{~km}$ are $1885-3700,4241-8482$ and $11,800-13,600$, respectively.

Thus the difference in the estimate of $2 \sigma$ from the two studies results in approximately a two- to six-fold difference in the estimate of neighbourhood size. Although the neighbourhood size estimate here is less than that obtained previously, it is still approximately an order of magnitude greater than estimates of effective population size ( 346 and 390 ) based on analysis of allele frequency variances in the populations of the ten initial release sites in Hawaii and Australia (Easteal, 1985a).

Easteal (1985a) and Easteal and Floyd (1985) have argued that the discrepancy between their estimates (based on "ecological" and "genetic" methods) results mainly from incorrect estimates 


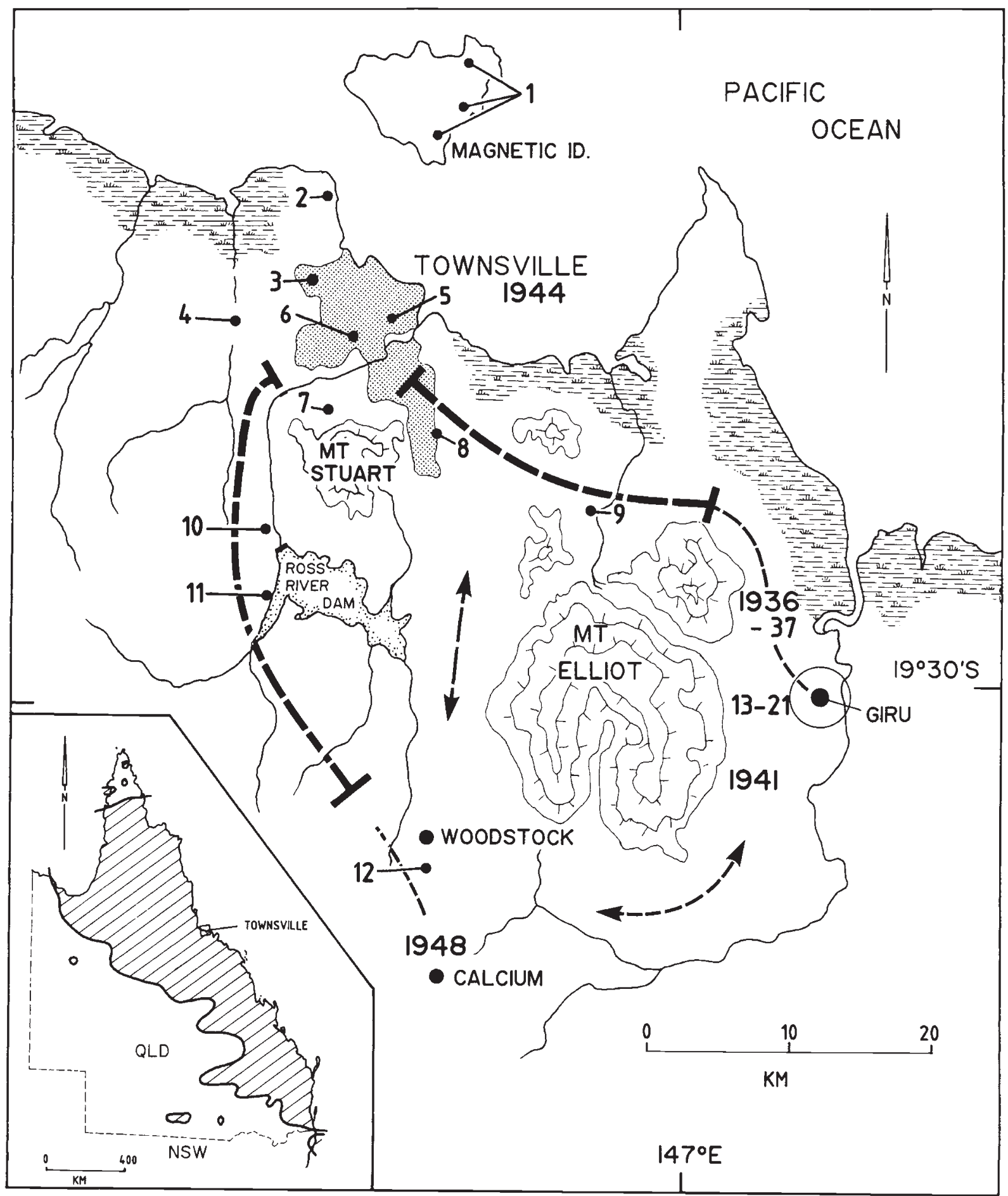

Figure 5 Spatial locations of the zones of introgression (bracketed heavy lines), and other possible paths of gene flow (arrowed lines). 
of the values of the ecological parameters important in determining neighbourhood size and not from an incorrect assumption of selective neutrality in the allele frequency variance analysis. The results of the present study suggest that a component of the previously noted discrepancy may have been due to an inaccurate estimate of gene flow rate. However, this component was not significant in the sense that, taking it into account, there remains an order of magnitude difference between the estimates, and this is still large enough to have a crucial effect on an understanding of population structure.

The conclusion drawn from the results of the allele frequency variance analysis is that genetic drift is an important force in determining population structure. The conclusion from the ecological analysis is that neighbourhood size is too large for genetic drift to be important and that there will be little if any differentiation among local populations at equilibrium, assuming selective neutrality (Wright, 1943).

The residual discrepancy may be due to errors in the estimation of population density, offspring number variance or sex ratio disparity. The potential for error in these parameters, as they were estimated by Easteal and Floyd (1985) and have been determined by other investigators, is large and likely to result in overestimates of neighbourhood size (Easteal and Floyd, 1985). In other studies gene flow rate is usually estimated as dispersal rate and thus tends also to give an overestimate of neighbourhood size.

Comparison of the results of this study and those of Easteal (1985a) and Easteal and Floyd (1985) shows that the extent of overestimation can be great enough to result in entirely erroneous conclusions about the genetic structure of populations and that this is true even when accurate estimates of gene flow rate can be obtained. The results caution against making inferences about genetic population structure based on ecological studies.

\footnotetext{
Acknowledgements I thank Rhondda, Doug and Sue Jones and the School of Biological Sciences at James Cook University of north Queensland for hospitality and use of facilities during the field work component of this project, and Megan Bateman for excellent laboratory assistance. I am grateful to John Oakeshott, Phil Anderson, the late Mike Sabath, an anonymous reviewer, and particularly Ian Boussy for stimulating and helpful discussion, advice and comment during the design of the project and the preparation of the manuscript. The work was supported in part by a grant from the Australian Research Grants Council.
}

\section{REFERENCES}

BAKER, A. E. M. 1981. Gene flow in house mice: introduction of a new allele into free living populations. Evolution, 35, 243-258.

CAVALLI-SFORZA, L. L. AND BODMER, W. F. 1971. The Genetics of Human Populations. Freeman, San Francisco.

COYNE, J. A., BOUSSY, I. A., PROUT, T., BRYANT, S. H., JONES, J. S. AND MOORE, J. A. 1982. Long-distance migration of Drosophila. Amer. Natur., 119, 589-595.

CRAWFORD, M. H., GONZALEZ, N. L., SCHANFIELD, M. S., DYKES, D. D., SKRADSKI, K. AND POLESKY, H. F. 1981. The black Caribs (Garifuna) of Livingston, Guatemala: Genetic markers and admixture estimates. Hum. Biol., 53, 87-103.

DALY, J. C. 1981. Effects of social organization and environmental diversity on determining the genetic structure of a population of the wild rabbit, Oryctolagus cuniculus. Evolution, 35, 689-706.

EANES, W. F. AND KOEHN, R. K. 1978. An analysis of genetic structure in the monarch butterfly, Danaus plexippus. Evolution, 32, 784-797.

EASTEAL, S. 1981. The history of introductions of Bufo marinus (Amphibia: Anura); a natural experiment in evolution. Biol. J. Linn. Soc., 16, 93-113.

EASTEAL, S. 1982. The genetics of introduced populations of the giant toad, Bufo marinus; a natural experiment in evolution. Ph.D. Thesis, Griffith University.

EASTEAL, S. 1985a. The ecological genetics of introduced populations of the giant toad, Bufo marinus. II. Effective population size. Genetics, 110, 107-122.

EASTEAL, S. 1985b. The ecological genetics of introduced populations of the giant toad Bufo marinus. III. Geographical patterns of variation. Evolution, 39: 1065-1075.

EASTEAL, S. AND FLOYD, R. B. 1985. The ecological genetics of introduced populations of the giant toad, Bufo marinus. Dispersal and neighbourhood size. Biol. J. Linn. Soc. (in press).

EASTEAL, S., VAN BEURDEN, E. K., FLOYD, R. B. AND SABATH, M. D. 1985. Continuing spread of Bufo marinus in Australia: Range expansion between 1974 and 1980. J. Herpetol., 19, 185-188.

EHRLICH, P. R. AND RAVEN, P. H. 1969. Differentiation of populations. Science, $165,1228-1232$.

ENDLER, J. A. 1977. Geographic Variation, Speciation and Clines. Princeton University Press, Princeton.

FLOYD, R. B., BOUGHTON, W. C., EASTEAL, S., SABATH, M. D. AND VAN BEURDEN, E. K. 1981. Distribution records of the marine toad (Bufo marinus). Part 1, Australia (2nd edition). AES Working Paper 3/81. School of Australian Environmental Studies, Griffith University.

FRANCO, M. H. L. P., WEIMER, T. A. AND SALZANO, F. M. 1981. Blood polymorphisms and racial admixture in two Brazilian populations. Amer. J. Phys. Anthrop. 58, 127-132.

GILL, D. E. 1978. Effective population size and interdemic migration rates in a metapopulation of the red-spotted newt, Notophthalamus vividescens (Rafinesque). Evolution, $32,839-849$.

HANDEL, S. N. 1983. Contrasting gene flow patterns and genetic subdivision in adjacent populations of Cucumis sativus (Cucurbitaceae). Evolution, 37, 760-771.

JONES, J. S., BRYANT, S. H., LEWONTIN, R. C., MOORE, J. A. AND PROUT, T. 1981. Gene flow and geographical distribution of a molecular polymorphism in Drosophila pseudoobscura. Genetics, 98, 157-178. 
LARSON, A., WAKE, D. B. AND YANEV, K. P. 1984. Measuring gene fiow among populations having high levels of genetic fragmentation. Genetics, 106, 293-308.

MAYR, E. 1963. Animal Species and Evolution. Harvard Univ. Press, Cambridge, Mass.

MCCAULEY, D. E. 1983. Gene flow distances in natural populations of Tetraopes tetraophthalamus. Evolution, 37, 12391246.

MUNGOMERY, R. W. 1937. The present situation regarding the giant American toad in Queensland. Cane Grower's Quart. Bull., 5, 12.

NEI, M. 1978. Estimation of average heterozygosity and genetic distance from a small number of individuals. Genetics, 89 , 583-590.

PATTON, J. L. AND FEDER, J. H. 1981. Microspatial genetic heterogeneity in pocket gophers: Non random breeding and drift. Evolution, 35: 912-920.

SABATH, M. D., BOUGHTON, W. C. AND EASTEAL, S. 1981. Expansion of the range of the introduced toad Bufo marinus in Australia from 1935 to 1974. Copeia, 1981, 676-680.

SCHAAL, B. A. 1980. Measurement of gene flow in Lupinus texensis. Nature, 284, 450-451.

SINGLETON, G. E. AND HAY, D. A. 1983. The effect of social organization on reproductive success and gene flow in colonies of wild house mice, Mus musculus. Behav. Ecol. Sociobiol., 11, 49-56.
SLATKIN, M. 1981. Estimating levels of gene flow in natural populations. Genetics, 99, 323-321.

SNEATH, P. H. A. AND SOKAL, R. R. 1973. Numerical Taxonomy. Freeman, San Francisco.

STANLEY, S. M. 1979. Microevolution: Pattern and Process. Freeman, San Francisco.

WARD, R. H. AND NEEL, J. V. 1976. The genetic structure of a tribal population, the Yanomama indians. XIV. Clines and their interpretation. Genetics, 82, 103-121.

WORKMAN, P. L. 1973. Genetic analysis of hybrid populations. In Methods and Theories of Anthropological Genetics, ed. M. H. Crawford and P. L. Workman, pp 117-150. University of New Mexico Press, Albuquerque.

WORKMAN, P. L. AND NISWANDER, J. D. 1969. Population studies on southwestern Indian tribes. II. Local genetic differentiation in the Papago. Amer. J. Hum. Gent., 22, 24-49.

WRIGHT, S. 1943. Isolation by distance. Genetics, 16, 97-159.

ZERA, A. J. 1981. Genetic structure of two species of waterstriders (Gerridae: Hemiptera) with differing degrees of winglessness. Evolution, 35, 218-226. 